\title{
The Treatment of Adjectives in Tourism Websites: A Comparative Study of the Jordanian, European and Asian Official Tourism Websites
}

\author{
Juhaina Maen Al-Issawi \\ The University of Jordan, Amman, Jordan \\ E-mail: juhainaalissawi@yahoo.com
}

Received: August 2, 2020 Accepted: September 9, 2020 Published: September 21, 2020

doi:10.5296/ijl.v12i5.17513

URL: https://doi.org/10.5296/ijl.v12i5.17513

\begin{abstract}
This study aims at examining how the lexical choice of a given discourse is determined by different factors such as the type of the discourse, the content and the medium of the message, and the ideological perspectives of the tourism persuader. More specifically, the study focuses on selecting adjectives in the Jordanian tourism official websites compared to European and Asian counterparts. The finding of the study shows that adjective lexical selection, together with their collocational behavior plays a crucial role in the tourism promotional discourse. The lexical choice of adjectives is also semantically restricted in that only limited meanings of the adjectives in the discourse are used. Accordingly, the vocabulary of the Jordanian tourism websites is characterized by the co-presence of two main types of adjectives: the descriptive adjectives, describing details about the targeted destination; and evaluative adjectives, conveying positive attitudes.
\end{abstract}

Keywords: Lexical choice, Adjectives, Description, Evaluation, Sematic restrictions

\section{Introduction}

The methodology of multimodal analysis of tourism websites suggests that the design of these websites encompasses textual and visual discourse. Maci (2007) contained that the layout that is constructed of texts surrounded by visual elements is regarded as semiotic discourse. Such a type of framework helps in describing and depicting the world as having either "real" or "ideal" representation (ibid: 54). Indeed, the tourism language is "a specialized discourse" based on the fact that it has specified terminologies, a unique semantic content, and a distinctive register. Besides, it follows particular syntactic rules and structures (Merkaj, 2013: 321). Accordingly, 
the linguistic analysis of tourism discourse is very significant in assessing the textual differences as an indication that underlies linguistic strategies (Gotti, 2006). Even though the language of tourism discourse resembles the language of any other discourse, yet the language of tourism websites appears to be exceptionally persuasive. Therefore, lexical items' choice is argued to be unique and a bit different from the other type of specialized discourses. Likewise, the structure and form of sentences are also distinctive.

Some previous studies highlighted the importance of using attractive and persuasive linguistic techniques embodied in the use of lexis. Bin Salim, Ibrahim, and Hassan (2012), for example, maintained that tourism promotions utilized different linguistic techniques to describe the targeted destination in an attempt to attract, persuade, and encourage the potential tourist to visit or revisit the destination kiss (2018), on the other hand, investigated the role of the lexical and grammatical persuasive discourse function of tourism texts and the extent to which the different lexical and grammatical choices affected the customers' perception and attitude. The study found that lexical choices are considered a powerful means of persuasion. The use of attribute-noun phrases and intensifying adverbial-adjectival clusters are effective tourism discourse styles. Likewise, Topler (2018) examined the linguistic aspects of the advertising texts existed in European tourism websites. The study concluded that the European tourism discourse's lexical choice affected positively the local branding of the country that contributed to attracting the business. The researcher maintained that the tourism language is considered a tool utilized in the tourism industry, which has an essential role in "sustainable destination development."

Salim and Som (2018), on the other hand, discussed the importance of official tourism websites in modeling the tourist's values and norms of the targeted destination. The study found that tourism promotion and marketing the destination on the websites depend mainly on persuasive techniques (both linguistic and visual), which create schemata toward the destination. Therefore, the linguistic aspects and visual images contribute to portraying the positive aspect of the targeted destination. Some researchers conducted contrastive studies in which they aimed at examining the persuasive linguistic techniques used in the official tourism websites. Malenkina and Ivanov (2018) investigated the linguistic techniques used in the seventeen webpages of Spanish official websites. Afterward, the Spanish corpus was compared to the English parallel ones. The finding showed metadiscoursal markers found in the form of a specific vocabulary of tourism discourse. The corpus analysis showed the extensive use of subjective adjectives, proper nouns, and interpersonal markers that create direct contact with the addresses.

Hence, the study sets out to explain the verbal techniques used in the Jordanian official tourism websites and then compare them to the European and Asian ones. The following sections are then devoted to showing how the linguistic techniques are utilized in different frequencies by the local (i.e., Jordanian) and the international (i.e., European and Asian) tourism websites. Consequently, the present study has cross-cultural tourist communication implications in that it interprets the data from a linguistic and cultural perspective. Hannam and Knox (2005) stated that combining textual and visual analysis (i.e., semiotic analysis) allows for recognizing the several layers of meaning of a given discourse. In other words, even though the relationship 
between these layers of meanings is arbitrary, yet they may bound by specific cultural contexts. The subsequent analysis then focuses on the use of different types of adjectives as one of the main linguistic techniques in the tourism discourse.

\section{Aim of the Study}

This study aimed to identify the descriptive and evaluative adjectives frequently used in Jordanian online news websites. It also aims at investigating the behavior of collocational adjectives more specifically. The following subsection describes the source of data, materials, procedures, and data analysis.

\section{Methodology}

The present study is concerned with adjectives in the discourse of tourism, one of the critical sectors in the Jordanian economy. Nowadays, tourism is a fast-growing sector on websites (Marcussen, 2008). Therefore, the data of the present study were retrieved from the most popular Jordanian tourism websites. The Jordanian websites where the data is extracted from are: Jordan Inbound Tour Operators Association (info@jitoa.org), Ministry of Tourism and Antiquities (contacts@mota.gov.jo), Department of Antiquities (info@doa.gov.jo), Jordan Tourism Board (info@visitjordan.com), Jordan Tour Guides Association (info@tourguides.com.jo), Jordan Society of Tourism and Travel Agents (info@jsta.org.jo), Jordan Hotel Association (jha@johotels.org), Jordan Restaurant Association (Info@jra.jo), Petra Development and Tourism Region Authority (info@pra.gov.jo), Tourist Jordan: The Insider's Guide (touristjordan.com), and Jordan Direct Tours (jdtours.com/jordan/). However, the European tourism promotions are extracted from the following websites: Europe Travel Guide (europe-tourism.org), and The Official Travel Portal of Europe (visiteurope.com/en/). Whereas the Asian tourism promotions are extracted from the following websites: Asia Travel Guide (roughguides.com/destinations/asia/), and Inside Asia Tours (insideasiatours.com/southeast-asia/magazine/). These websites were selected since they are accessible and provide travel information for tourists. Moreover, they are qualified sources, and it was convenient to collect the data in an attempt to discover the adjective occurrence and be up to date.

\section{The Lexical Choice}

Tourism discourse is recognized as a specialized discourse in that it has its unique linguistic features such as complex sentences, technical terminology, and modality (Maci, 2012). Indeed, Jones (2012) proclaimed that the language of tourism could be identified as a unique language (LSP) not because it uses linguistic elements absent from the general discourse. Instead, it exploits these elements found in the general discourse. Likewise, he added that the fact that tourism is a specialized type of language does not contradict the fact that it is also regarded as an advertising language that targets laypeople. Lexical choices are one of the main ways that characterize this specialized type of discourse. According to Wanner and Bateman (1990), the lexical choice reflects different aspects of the message highlighted by the producer and therefore suggests different degrees of salience. Likewise, Stede (1993) insisted on the massive 
role of word choice as a mirror for the speaker's intention. Accordingly, they are required to fit adequately in the context where they have occurred.

However, not all lexical items are the right candidate for analysis. Indeed, the analysis of a given discourse is usually targeted only content words. Accordingly, the lexical choice is mainly dependent on choosing content words (e.g., verbs, nouns, adjectives, and adverbs) over function words (e.g., prepositions, determiners, pronouns, etc.). The reliance on the content words is justified by the fact that "those are the words that help us form a picture in our head; they give us the contents of our story and tell our listener where to focus his or her attention" (Moye, 2019:1). Hence, the content words carry the primary information of any discourse, whereas the function words are only used to keep the syntactic well-formedness of the sentence. Subsequently, this section is devoted to describing the main categories of lexical words (i.e., content words) in the tourism discourse. The focus, therefore, is on adjectives in Jordanian tourism discourse compared to the European and Asian ones.

\subsection{Adjectives in Tourism Discourse}

Traditionally, adjectives have often been disregarded in lexical studies in favor of other types of parts of speech (e.g., verbs or nouns). Baker (2003) asserted that adjectives are only modifiers that modify or describe nouns or pronouns and never used as meaning conveyors. However, L'Homme (2002) insisted on the importance of adjectives and how they should be considered in the theoretical analysis. He justified their importance by stating that "they provide several clues on the meaning of noun terms and criteria to support an analysis performed by terminographer" (ibid: 6). Accordingly, they are responsible for categorizing entities or even events based on their qualities. They also contribute to disambiguating lexical items. Roughly speaking, there are different ways of classifying adjectives based on what criteria have been adopted (Quirk, Greenbaum, Leech, and Svartvik, 1972).

Regardless of these different criteria, almost all adjectives fall mainly under two main adjectives. These are descriptive adjectives (i.e., objective) and evaluative adjectives (i.e., subjective). The former provides factual information that cannot be measured. In contrast, the later provides information that can be measured and compared and therefore, can appear in their comparative and superlative forms (Muñoz, 2019). More specifically, adjectives used to describe entities are called descriptive adjectives, while those used to express the writer's adjustment are called evaluative adjectives. It is argued that descriptive and evaluative adjectives are found in almost all types of discourses since they are mainly used to explain then evaluate people, things, and places. Therefore, the study focuses (by not restricted) to these two categories of adjectives since they are sufficient to describe the subject of matter. Despite the different types of adjectives, they all are fundamental in describing and distinguishing between concepts. They also contribute to adding a personal touch to the description (Davies, Lingwood, and Arunachalam, 2019).

Generally speaking, adjectives are an integral persuasive tool that is used to affect the readers to accept a particular point of view. Accordingly, they direct the readers' attention and situate them to feel a certain way about a particular issue. As aforementioned, adjectives are highly efficient and practical tools, especially in marketing. Ebaid (2018) stated that they are essential 
to the extent that marketers and marketing agencies are urged to use them even solely to name merchandise. Similarly, Calvi (2000) declared that tourist's information is essential to persuade potential tourists to purchase tourism services. Accordingly, the tourism language can be argued to be informative as well as persuasive. However, that is not to say that the tourism language is persuasive because it loses its authenticity, rather it depends heavily on using a particular technique of description. That is to say, and the writer makes a combination of performative as well as persuasive discourse. Furthermore, adjectives are also proved to be cultural-specific terms that mirror the socio-cultural aspects of the producers. Marza (2011) asserted that adjectives' influential roles are grounded in syntactic behavior such as the collocational patterns and classifications, which are better understood in the way they are depicted in the genre.

Nevertheless, the use of adjectives in all kinds is essential in forming any tourism discourse. As such, adjectives are utilized as determiners for the tourism discourse type as descriptive, evaluative, informative, persuasive, or even aesthetic. Therefore, linguists such as Ding (2008) insisted on the importance of analyzing tourism discourses as a rich source for examining adjectives despite their types, whether descriptive, superlative, or imperative. Subsequently, descriptive and evaluative adjectives are combined linguistic techniques in the English tourism discourse. In other words, while writers describe things, they make judgments about these things at the same time. That is to say; there is no way to describe things detached from the producers' judgments.

The following section attempts to shed light on the critical role of adjectives in the tourism discourse as one of its linguistics characterizations. It also seeks to explain the role of adjectives in this specific subdomain (i.e., tourism) compared to the general domain of language. More specifically, it examines the role of adjectivization of a different specific domain, namely: the local and international tourism domains. In other words, this section proposes measurement of a critical concept of adjectivization in the local promotional discourse by comparing its usage to the international promotional discourse. The present section provides a descriptive analysis of each domain (i.e., Jordanian vs. European and Asian tourism websites) with illustrative examples regarding this respect.

\subsubsection{Descriptive Adjectives}

Generally speaking, adjectives are the least lexical category that has been studied in linguistics compared to other lexical categories as verbs and nouns. Bakhshandeh and Allen (2015) insisted on the importance of adjectives in describing and modifying other words (e.g., nouns). Accordingly, adjectives are regarded as essential tools that contribute to transmitting a subjective meaning to the sentences. They are used to describe different features of other entities. However, descriptive adjectives are regarded as the largest amongst all other types of adjectives. It can be said that it is an endless category of adjectives in the sense that there are abundant adjectives to describe almost all nouns.

The following are the most frequently used types of descriptive adjectives found in the Jordanian tourism websites. As indicated by its name, descriptive adjectives are utilized to describe quality, size, color, shape, sound, feeling, or even personal traits. They also can be 
used to describe religious and historical places. Now consider the sequences of examples mentioned below, which contain descriptive adjectives of various types:

(1) a. Amman, the capital of Jordan, ... Amman's neighborhoods are diverse and range in cultural and historical context from hustle and bustle of the downtown markets to the art galleries of Jabal Lweibdeh and the modern shopping district of Abdali. http://international.visitjordan.com/Wheretogo/Amman.aspx

b. Umm El Jimal is considered an Arabian Oasis for the desert caravans...... History of this city goes back to the Romanian Byzantine Age. http://international.visitjordan.com/whattodo/HistoryCulture.aspx

c. Jerash is an amazing blend of Greco-Roman and Oriental influences. Also, every year Jerash hosts the Jerash Festival of Culture and Arts, a three-week summer program filled with folk dance, music, and theatrical performances. http://international.visitjordan.com/Wheretogo/Jerash.aspx

These examples mentioned above, the adjectives appear to contribute to the interpretation of the sentences' meanings to a high degree. The underlined adjectives' diverse, range cultural, historical, hustle, bustle, art, and modern' contained in (1, a), for example, are allocated to describe the culture of the described city Amman positively. The already mentioned lexical items are a few examples of adjectives that Jordanian tourism websites use to describe their culture. Likewise, the fact that Oasis and Age in $(1, \mathrm{~b})$, are being described as 'Arabian' and 'Romanian' Byzantine help make the place being described, Umm el Jimal, stand out from the rest places. Furthermore, Jerash's influence is being described as 'Greco-Roman' and 'Oriental' in (1, c) add a better idea about the cultural and historical background of the Jerash.

(2) a. The Dead Sea is the warm, soothing, super salty water itself - some ten times saltier than sea water, and rich in chloride salts of magnesium, sodium, potassium, bromine and several others. http://international.visitjordan.com/Wheretogo/TheDeadSea.aspx

b. Petra is also known as the rose-red city, a name it gets from the wonderful colour of the rock from which many of the city's structures were carved. http://visitpetra.jo/Pages/viewpage.aspx

In these examples, the adjectives resemble the previous examples in the sense that they belong to the same category of descriptive adjectives. However, the descriptive adjectives in the previous examples describe the cultural and historical aspects of the promoted destination. In contrast, the descriptive adjectives in this example describe substances and properties of the promoted destination. Adjectives like 'warm, soothing, super salty and rich'; and 'rose-red, and wonderful colour' as those in (2. a, b) above help make the description more visual and vivid. Therefore, such a description appeals more to the readers' senses, making the readers feel as if they see or perceive what is being described.

(3) a. .... the Baptism Site commission welcomes pilgrims from all around the world seeking spiritual connection to biblical times, a glimpse of history or a chance to be baptized where Jesus was so many years ago. http://international.visitjordan.com/Wheretogo/TheBaptismSite 
b. Bethany and other nearby places formed part of the early Christian pilgrimage route between Jerusalem, the Jordan River and Mount Nebo. http://www.tourguides.com.jo/index

Descriptive adjectives can also be ascribed to designate religious places and rituals. As it is seen from the examples mentioned above, the underlined adjectives in (3.a) 'Baptism, spiritual, and biblical' attributed different ritual concepts and practices designated for particular culture. These adjectives describe different ways of celebrating a culture or religion. Descriptive adjectives can denote a religion such as the case of the underline 'Christian' word in example (3.b) above. These adjectives contribute in adding qualities and information to the modified words.

(4) a. Aqaba is a beach town with Jordanian appeal. Equipped with the local watering holes, to water sports, and a historical flair for those looking to revisit the past Aqaba is a delightful complement to the metropolitan appeal of Amman. http://international.visitjordan.com/Wheretogo/Aqaba.aspx

b. The sprawling pine forests of the Ajlun-Dibbine area and the towering Ayyubid castle at Ajlun, which helped to defeat the Crusaders eight centuries ago. Locals often take advantage of the green landscapes of Ajlun to take a break from city life and connect with nature. http://international.visitjordan.com/Wheretogo/Ajlun.aspx

So far, based on the previously mentioned examples, it seems that descriptive adjectives are good candidates for describing nature. The underlined adjectives in (4) can only be interpreted in their underlying meanings as descriptive adjectives that describe nature. Descriptive adjectives as in (4.a) 'beach, local watering, and delightful'; and in (4.b) 'sprawling pine, towering Ayyubid, and green' say something about the beauty of natural places and scenes of different places in Jordan. As can be noticed from the examples above, descriptive adjectives can be collocated with other adjectives to form combined adjectives. Galeas (2003) contained that when adjectives are combined to create a single modifier, it is easier for the reader to perceive their meanings. The compound adjectives, however, is not restricted to the adjectives that describe nature. Almost all adjectives can be combined to create specific meanings, as shown in the following examples.

(5) a. An ancient Crusader stronghold, Karak sits $900 \mathrm{~m}$ above sea level and lies inside the walls of the old city. http://international.visitjordan.com/Wheretogo/Kerak.aspx

b. Also, every year Jerash hosts the Jerash Festival of Culture and Arts, a three-week summer program filled with folk dance, music, and theatrical performances. http://international.visitjordan.com/Wheretogo/Jerash.aspx

c. As-Salt is a thriving city situated North West of the capital Amman. Built on three main mountains (the cadital, gadaa and salalem), surrounded by the city square, Al-Salt is enclosed by breathtaking views and is a wonderful contrast to some of the westernized sites of Amman. http://international.visitjordan.com/Wheretogo/AsSalt.aspx

Descriptive adjectives like 'ancient Crusader, and old in (5. a) are used her to express time. An adjective can also be combined to describe time as in (5. b). as can be seen from the example, 
the number 'three' is preceded by the nouns week and summer to indicate the period in a singular form separated by a hyphen. Similar to the adjectives of time, the descriptive adjective can also be used to indicate locations. If the adjectives above 'situated North West, surrounded, and enclosed' in (5. c) are examined, it will be noticed that such adjectives are allocated to attribute location.

It is worth mentioning that there is no difference in the adjectival behavior in the Jordanian tourism websites from those found in the European and Asian ones. The data analysis shows that both descriptive and evaluative adjectives are used in the official European websites. The study examines the signification of descriptive and evaluative adjectives since they are so exclusive and almost all adjectives can be identified as one of these two main categories. As a result, both description and evaluative adjectives are integrated and interlinked in any given discourse. Regarding descriptive adjectives, examine carefully the following examples extracted from the European tourism websites.

(6) a. Italy is located in Southern Europe, it is a boot shaped peninsula located on the Mediterranean Sea. To the north; Italy borders Slovenia, Austria, Switzerland and France. It has got two large islands, Sardinia and Sicily, and roughly 70 smaller islands. There are two independent city-states within Italy: the Republic of San Marino and the Vatican City in Rome. https://europe-tourism.org/italy/

b. Ostia used to be the Roman Port, it is located south of Rome on the coast. The archaeological excavations are a must see, where you will admire a theatre, baths, temples and mosaics of ancient Rome. https://europe-tourism.org/italy/

c. Germany has a diverse landscape of rich culture and history. In the heart of Europe, fairytale castles rest high on craggy mountaintops, and tiny romantic villages enchant with chocolate box charm and the typical German Gemütlichkeit. https://visiteurope.com/en/destination/germany/

d. Explore the Carpathian garden with its ancient traditions, folkloric fairs and gastronomic delights. Turn south to explore Bucharest, the capital of Romania and find a mix of tradition and modernity, of Orient and Occident. Discover the Danube River, the southern border of Romania and trace its path to the Black Sea where it transforms into a unique delta. https://visiteurope.com/en/destination/romania/

The previously mentioned adjectives in (6, a-d) 'Southern, boot shape, Mediterranean, north, large, small'; 'roman, south, archaeological, mosaics'; 'diverse, rich, fairytale, tiny romantic, chocolate box'; and 'ancient, folkloric, gastronomic, capital, mix, southern, black' are descriptive that designate different concepts. As can be clearly noticed, these adjectives give description of space, size, shape direction, color, and even substances. These adjectives add to the preciseness of the description which might help in creating certain image in the mind of the readers. Such mental image is called 'schema' and help in reinforcing the image of the described places. This is more likely contributed in the enhancement and portrayal of the positive tourist image who is new to the city and might attract the tourists as a result (Mccartney, Butler, and Bennett, 2009). 
As mentioned earlier, there is no significant difference in the adjective behavior between the local (i.e., Jordanian) and the international (i.e., European and Asian) tourism websites. It can be evident in the following examples extracted from Asian tourism websites, which shows the extensive use of descriptive adjectives. The underlined adjectives 'first, extraordinary density, grey, busy'; 'major, Taoist, coastal, couple, swath, lots, ferry'; 'fertile Red, Vietnamese, cultural, modern, capital, center, northern'; and 'short, modern throng, Southeast' in (7, a-d) described different concepts. It is worth mention that adjectives can collocate with another adjective forming one modifier for further descriptive clarification.

(7) a. The first thing that strikes visitors to the country is the extraordinary density of its population. In much of China, villages, towns and cities seem to sprawl endlessly into one another along the grey arteries of busy expressways. https://www.roughguides.com/destinations/asia/

b. Tai Shan, one of the major pivots of the Taoist religion; and the coastal city of Qingdao, which offers a couple of beaches, swath of colonial architecture, lots of beer and seafood, and a ferry service to South Korea. https://www.roughguides.com/destinations/asia/

c. The fertile Red River valley has been the home of the Vietnamese people for almost 5,000 years, and it remains the cultural heartland of the modern Vietnamese nation. With the capital Hanoi at its center, northern Vietnam offers the best of all worlds. https://www.insideasiatours.com/southeast-asia/regions/northern-vietnam/

d. Though just a short flight from the modern throng of Bangkok, arriving in Myanmar is akin to travelling back through time to a Southeast Asia of the 1980s: https://www.insideasiatours.com/myanmar/destinations/

\subsubsection{Evaluative Adjectives}

This section examines another class of adjectives is called evaluative adjectives, which expresses both qualitative evaluation and adjectives that describe amazement. Evaluative adjectives are used to express the speakers' and writers' viewpoints or feelings towards what they are talking about. Therefore, Hunston and Thompson (2000) asserted that the use of adjectives as evaluative is a complex phenomenon because it depends on the writers' attitudes, feelings, and viewpoints. According to Kerbrat-Orecchioni (1980) classification, subjective adjectives are divided into emotional and evaluative adjectives. For this paper, evaluative adjectives used in the sense that they represent the writers'/speakers' subjective attitudes.

Soler (2002) maintained that evaluative adjectives might indicate the favorable or unfavorable stance of the writers or speakers towards specific issues. Regarding tourism discourse, evaluative adjectives are considered one of the essential tools that play a critical role in attracting potential tourists' attention and persuading them to travel. Therefore, the choice of certain adjectives over others with the availability of different ways to describe nouns reflects the writers' attitude. The following are illustrative examples that are extracted from Jordanian tourism websites. 
(8) a. Amman, the capital of Jordan, is a fascinating city of contrasts - a unique blend of old and new, situated on a hilly area between the desert and the fertile Jordan Valley. In the commercial heart of the city, ultra-modern buildings, hotels, smart restaurants, art galleries and boutiques rub shoulders comfortably with traditional coffee shops and tiny artisans' workshops. http://international.visitjordan.com/Wheretogo/Amman.

b. Jerash is an amazing blend of Greco-Roman and Oriental influences. A great place to visit during the spring with its beautiful rolling hills and lush greenery, Jerash has a rhythm not seen anywhere else in Jordan. http://international.visitjordan.com/Wheretogo/Jerash.

c. Comfortably perched atop of mountains, As-Salt maintains an authentic society based on affection, brotherhood, and love. The mountainside city also has significant historical relevance, most notably, as the regional capital of the Ottoman Empire. http://international.visitjordan.com/Wheretogo/AsSalt.

d. Mujib's sandstone cliffs are an ideal habitat for one of the most beautiful mountain goats in the world, the horned Ibex. http://international.visitjordan.com/Wheretogo/Wadi\%20Mujib.

e. A spectacular natural wonder the Dead Sea is perfect for religious tourism and fun in the sun with the family. http://international.visitjordan.com/Wheretogo/TheDeadSea.

The underlined adjectives in the examples mentioned above say something about the positive quality of the described destination. Adjectives like in (8, a-e) 'fascinating, unique, ultra-modern, fertile, smart, art, boutiques, rub, amazing, beautiful, Comfortably, authentic, significant, ideal, beautiful, spectacular, perfect' are considered to be evaluative in the sense that they are somehow express some quality judgment about the described destination. Morzycki (2012) argued that adjectives that belong to the evaluative class of adjectives encode a notion of extremeness in their lexical semantics. In other words, such adjectives indicate the ultimate point of the scale regarding what they are describing and concertizing.

Pierini (2009: 98) contained a central aspect of the tourism discourse: how to present the described issue positively, no matter whether it is described "implicitly or explicitly." The evaluative adjectives in (8), for example, are words that are highly evaluative and emphatic. Dann (1996) and Gotti (2007) justified that such adjectives intensify the positive features of promoted objects by stating that they should appeal to the recipients' emotions. Accordingly, by stimulating their emotions, the receivers are more motivated to act, such as purchasing some of the tourism services (Janoschka, 2004).

However, the situation is not always as simple as that. Sometimes there is an overlap between evaluative adjectives and those types of adjectives that entail aesthetic judgment of the experiencers. McNallyand Stojanovic (2015) asserted that evaluative and aesthetic adjectives have something in common that is the subjectivity of the judgment. Both are not dependent on factual statements. Instead, they are relative in the sense that they are solely dependent on personal experiences and judgments.

Beside the descriptive adjectives, the data showed that the European tourism websites promotions rely also on the extensive use of the evaluative adjectives. Such concluding remark 
goes in line with Pierini (2009) who stated that both types of adjectives are complementing each other in way that add coherence to the texts. Furthermore, adjectives in tourism texts are either allocated to describe items or events or to give evaluation. The idea can be clearer if the underlined adjectives below are examined.

(9) a. Lose yourself in articles about the many wonders of Europe, get inspired by galleries of stunning European sights, learn how to celebrate like the locals and browse through unique events, discover exciting routes to embark on during your trip, get to know typical products, and, if you have a flair for cooking, take note of the very best European recipes! https://visiteurope.com/en/experiences/

b. This destination is a haven for lovers of history and picturesque panoramas.

https://europe-tourism.org/a-day-in-san-marino/

c. France sits atop many travelers' wish lists. From the lights of Paris to the relaxing countryside, France is one of the most alluring countries in the world. https://visiteurope.com/en/destination/france/

d. If you love sun, sea, nature, fancy to experience a lavish lifestyle, then visit Capri; one of the most beautiful islands in the world. In the island of Capri you will find history, local flavours and typical colours, artisans shops and luxury boutiques, all this in a fun day that will leave a precious memory in your hearts. https://europe-tourism.org/italy/

As can be seen, the utilized vocabularies as in (9, a-d) 'stunning, unique, exciting'; 'haven, picturesque'; 'the most alluring'; and 'lavish, the most beautiful' are emphatic since they are highly evaluative. Such evaluative vocabularies focus only on the positive qualities of the described items. Dann (1996) and Gotti (2006) maintained that focusing only on the positive characteristics of tourism products or offered services is the general feature of tourism discourse. Such a technique is considered to be a successful one because it appeals more to the receivers and helps in motivating them to do actions (i.e., the purchase) (Janoschka, 2004). Such use of adjectivization reflects the combination of description and emotional evaluation as a persuasive force of the tourism web message.

The underlined adjectives in the following mentioned examples in (10, a-d) reflect the positive quality of the described objects. Adjectives like 'mysterious, exotic, pervasive, fascinating'; 'beautiful, brand-new, culmination, hard work, countless, superb new'; 'fantastic, stunning'; and 'spectacular, tumbling, verdant, dynamic, vividly, explosive, powerful, startlingly original' show the favorable stance of the writers towards the entity being described. Therefore, such adjectives are considered necessary in evaluating promoted places.

(10) a. International influence is only just gaining a foothold and the sense of the mysterious and exotic is still pervasive. After decades of political isolation, the pace of change in modern Myanmar, also known by its former name of Burma, is rapidly building, making this a fascinating time to visit and witness the transformation first-hand. https://www.insideasiatours.com/myanmar/destinations/ 
b. Our beautiful, brand-new brochure is the culmination of two years of hard work - exploring Southeast Asia, checking out new destinations, enjoying countless cultural experiences and road-testing our superb new itineraries. It's hard work, but someone's got to do it! https://www.roughguides.com/destinations/central-america-and-the-caribbean/

c. The end result is a fantastic source of inspiration for your next holiday to Myanmar, packed to the gills with adventure, excitement, stunning photography and wanderlust-inducing itineraries. https://www.insideasiatours.com/southeast-asia/about-us/brochures/

d. ... but away from the coast is spectacular mountains and rivers, tumbling waterfalls and cactus-strewn savannah plains. This verdant natural environment forms the backdrop to a dynamic cultural history in the island's towns and cities, illustrated most vividly by the explosive reggae scene, but also in the powerful expression of its artwork and the startlingly original flavours of its national cuisine.

\section{Concluding Remarks}

As above-mentioned, the main aim of the present study is to pinpoint the adjectival behavior in Jordanian tourism websites. The study examines the signification of descriptive and evaluative adjectives since they are so exclusive, and almost all adjectives can be identified as one of these two main categories. As a result, both description and evaluative adjectives are integrated and interlinked in any given discourse. Such a concluding remark goes in line with Pierini (2009), who stated that both types of adjectives complement each other in a way that adds coherence to the texts. Furthermore, adjectives in tourism texts are allocated to describe items or events or give an evaluation. Subsequently, the utilized vocabularies are emphatic since they are highly evaluative. Such evaluative vocabularies focus only on the positive qualities of the described items. Dann (1996) and Gotti (2006) maintained that focusing only on the positive characteristics of tourism products or offered services is the general feature of tourism discourse. Such a technique is considered to be a successful one because it appeals more to the receivers and helps in motivating them to do actions (i.e., the purchase) (Janoschka, 2004). Such use of adjectivization reflects the combination of description and emotional evaluation as a persuasive force of the tourism web message.

As long as the knowledge of the author is concerned, the field of tourism discourse is considered to be a weak area in terms of research in Jordan. Previous literature regarding tourism discourse in Jordan addressed the question of the tourism sector's ability to provide tangible benefits to the national economy. Hazbun and Waleed (2008) argued that tourism is an important and vital source of income for the local economy but without mentioning the strategic way to improve the tourism sector in Jordan. Similarly, Kreishan (2010) stated that the government should focus on economic policies to promote international tourism as a source of income growth in Jordan. On the other hand, Abu Tayeh and Mustafa (2018) focused on the existence of Crisis Management in national tourism strategies without suggesting any possible solution to overcome such crises. However, these pieces of research have neglected the importance of the different linguistic strategies that might enhance the tourism sector in Jordan. On the other hand, previous research tackled tourism discourse from different perspectives. Shiratuddin, Ibrahim, and Wong (2013) discussed the persuasive visual techniques in website 
design. Other studies such as Sattar's (2017) study tackled the issue from a pragmatic point of view through applying Grice Maxime's framework on the tourism discourse.

Hence, no previous research has compared the lexical choice between the local and the global tourism discourse, which distinguishes it from other studies. It can be achieved by comparing adjectives as they appear in tourism promotions in the Jordanian tourism official websites to the international ones, namely: European and Asian. More specifically, the comparison covers only the textual elements of tourism promotions embodied in the use of adjectives. Therefore, focusing on content analysis only has its own limitations. These limitations rely mostly on the fact that content analysis is regarded as descriptive methods of analysis that focused on the signs over the significations of these signs. In other words, the lexical analysis highlights the denotative (literal) meanings rather than the connotative (implied) ones. However, to avoid such a limitation, the semiotic analysis (i.e., visual signs interpretations) could be utilized for a broader analysis of the signification of the images included in these tourism websites. In addition, the study would be more comprehensive if the lexical analysis covers more word classes other than adjectives such as nouns, verbs, and adverbs. Including different word classes as well as the grammatical contextual restrictions of these words would be a fruitful area for further studies. However, the present study can be considered a solid background and starting point for subsequent research in the future.

The tourism sector is believed to be one of the significant sources of income and employment worldwide, including Jordan. Therefore, there is always a strong need to enhance this sector's investment as one of the country's primary financial resources instead of relying only on one source or product such as Crude Oil (Faladeobalade and Dubey 2014). Accordingly, the government should pay more attention to tourism planning and marketing policies to promote international tourism as a potential source of income growth in the country in the long run (Kreishan 2010). Therefore, tourism needs to be expanded through official public discourse (Hazbun, 2008). Wyllie (2011) insisted on the importance of studying tourism as a global activity with its economic significance. Added to the size and economic significance, tourism is worth studying for other reasons such as understanding the bound humanistic characteristics of people worldwide, such as social, cultural, and political consequences, which cannot be ignored. Accordingly, it is argued that investigating tourism discourse contributes to understanding ourselves and the times in which we live (ibid: 3). Such type of tourism is called heritage tourism, which depends heavily on understanding tourists' motivation to visiting incent places and try to highlight them through tourism advertising. In doing so, tourism promotion designers can exploit this aspect (i.e., tourists' longing to spaces presenting history) to the marketing of these sites (Poria, Butler, and Airey, 2004).

For the reasons mentioned above, it is necessary to develop tourism advertising and promotions in Jordan. Since the tourism websites are accessed globally, analyzing the textual elements of the Jordanian tourism official websites and comparing them to the international ones might help find the most effective tourism advertising (linguistic and paralinguistic) strategies. These strategies might be a guideline for the promotion designers to focus on and hence improve tourism advertising and, in turn, increase the country's income. Hawkins, Sedaca, Khoury, Baggili, Ion, and Karwacki (2013), for example, assert that Jordan stands 
behind its neighbor countries such as Lebanon, Syria, and Egypt in terms of attracting the tourism sector. In other words, Jordan has failed to drag Arab and Gulf visitors to choose Jordan as a holiday destination. Accordingly, the designers of the Jordanian tourism website should work hard to advance the sector to meet the needs of potential visitors. Hence, Jordanian tourism websites need to appeal to customers in the sense that they should provide the information needed convincingly.

Added to that, the tourists' opinion and point of view about what factors that affect their decision of visiting Jordan reflects the efficiency of the strategies used in the tourism official websites. Such analyses might provide a good vision for the tourism promotion designers in the country to work harder in improving the tourism sector both locally and internationally. Cerutti and Piva (2016), for example, contained that tourists' opinions and reviews can be regarded as a useful source of information for tourism destination decisions. Such reviews outline the needs and demands of the visitor, which in turn help enhance the promotions of the tourism destinations that meet the expectations of the potential future tourists. Therefore, the tourism website designer should acknowledge the active role of tourists' feedback on tourism websites and their personal experience during their destination search journey to develop and expand today's online tourist technologies to improve countries' position on the tourist market.

Furthermore, the study has an empirical implication for educational development and practices. In other words, the discussion of tourism discourse gives the teachers ideas about developing strategies and techniques for the planes that needed to be done. Hence, a good strategic plan can improve student outcomes. The study might also enable the students to acquire an up-to-date tourism education. Amoah and Baum (1997: 7) insisted on the critical role of integrating tourism experiences within the academic educational components as means that bridge the way between industry and education. Paving the way between tourism and education is regarded as one way of long-term planning that might contribute positively to sustainable tourism development. Accordingly, it is vital to increase the tourism education and instruction in an attempt to improve tourism skills to keep the positive tourism image. Once the educational tourism awareness is established, tourism, in this case, can be transfer from theory into practice, which is the primary purpose of the present study.

\section{References}

Baker, M. (2003). Lexical categories: Verbs, nouns and adjectives. Cambridge: Cambridge University Press.

Bakhshandeh, O., \& Allen, J. (2015). From adjective glosses to attribute concepts: Learning different aspects that an adjective can describe. Proceedings of the 11th International Conference on Computational Semantics (pp. 23-33).

Bin Salim, M., Ibrahim, N., \& Hassan, H. (2012). Language for tourism: A review of literature. Social and Behavioral Sciences, 66, 136-143.

Calvi, M. (2000). El léxico del turismo. Universidad de Bérgamo. Retrieved November 21, 2019, from http://www.ub.es/filhis/culturele/turismo.html

Dann, G. M. (1996). The language of tourism: A sociolinguistic perspective. Wallingford: CAB International. 


\section{Macrothink}

International Journal of Linguistics

ISSN 1948-5425

2020, Vol. 12, No. 5

Davies, C., Lingwood, J., \& Arunachalam, S. (2019). Adjective forms and functions in British English child-directed speech. Journal of Child Language, 1-43.

Ding, D. (2008). Features and tourism English and its translation. Shanghai: Shanghai Jiao Tong University Press.

Ebaid, H. (2018). Adjectives as Persuasive Tools: The Case of Product Naming. Open Journal of Modern Linguistics, 8(6), 262-293.

Galeas, G. (2003). Compound adjectives in English: The type lion-hearted and good-natured. Studi Itabani di Linguistica Teonca e Applicata, 32(1), 31-43.

Gotti, M. (2007). The language of tourism as specialized discourse. In P. Oriana, \& F. Sabrina (Eds.), Translating Tourism Linguistic / Cultural Representations (pp. 15-34). Trento, Editrice Università degli Studi di Trento.

Hannam, K., \& Knox, D. (2005). Discourse analysis in tourism research a critical perspective. Tourism Recreation Research, 30(2), 23-30.

Hunston, S., \& Thompson, G. (2000). Evaluation in text: Authorial stance and the construction of discourse. Oxford: Oxford University Press.

Janoschka, A. (2004). Web advertising: New forms of communication on the internet. Amsterdam: Benjamins.

Jones, R. (2012). Discourse analysis. United Kingdom: Routledge.

Kang, N., \& Yu, Q. (2011). Corpus-based stylistic analysis of tourism English. Journal of Language Teaching and Research, 2(1), 129-136.

Kerbrat-Orecchioni, C. (1980). L' enunciation de la subjectivité dans le langage. Paris: Armand Colin.

Kiss, I. (2018). The persuasive discourse function in the language of tourism argumentum. Debreceni Egyetemi Kiadó, (14), 150-162.

L'Homme, M. C. (2002). What can verbs and adjectives tell us about terms?. Paper presented at Terminology and Knowledge Engineering conference (TKE). Nancy: France.

Maci, S. (2007). Virtual Touring: The Web-Language of Tourism. Linguistica e Filologia, 25, 41-65.

Maci, S. (2012). Tourism as a specialised discourse: the case of normative guidelines in the European Union. Token: A Journal of English Linguistics, 1, 37-58.

Malenkina, N., \& Ivanov, S. (2018). A Linguistic analysis of the official tourism websites of the seventeen Spanish autonomous communities. Journal of Destination Marketing and Management, 1-82.

Marcussen, C. (2008). Trends in European Internet distribution of travel and tourism services. Denmark: Centre for Regional and Tourism Research. Retrieved from http://www.crt.dk/uk/staff/chm/trends.htm 


\section{I Macrothink}

International Journal of Linguistics

ISSN 1948-5425

2020, Vol. 12, No. 5

Marza, N. (2011). A comprehensive corpus-based study of the use of evaluative adjectives in promotional hotel websites. Odisea: Revista de Estudios Ingleses, 12, 97-124.

McNally, L., \& Stojanovic, F. (2015). Aesthetic adjectives. In J. Young (Ed.), Semantics of aesthetic judgement. Oxford: Oxford University Press.

Merkaj, L. (2013). Tourist communication: A specialized discourse with difficulties in translation. European Scientific Journal, 2, 321-325.

Morzycki, M. (2012). Adjectival extremeness: Degree modification and contextually restricted scales. Natural Language \& Linguistic Theory, 30(2), 567-609.

Moye, F. (2019). Content words and function words. Retrieved December 14, 2019, from https://www.academia.edu/6097277/Content_Words_and_Function_Words

Muñoz, D. (2019). Adjectives and their keyness: A corpus-based analysis in English tourism. Corpora, 14(3), 1-30.

Pierini, P. (2009). Adjectives in tourism English on the web: A corpus-based study. Círculo de Lingüística Aplicada a la Comunicación (CLAC), 93-116.

Quirk, R., Greenbaum, S., Leech G., \& Svartvik, J. (1972). A Grammar of Contemporary English. London/New York: Longman.

Salim, M., \& Som, A. (2018). Shaping tourist destinations through language and visual elements on tourism websites: A tourism discourse perspective. International Journal of Engineering and Technology, 7(4), 364-369.

Soler, V. (2002). Analysing adjectives in scientific discourse: An exploratory study with educational applications for Spanish speakers at advanced university level. English for Specific Purposes, 21(2), 145-165.

Stede, M. (1993). Lexical choice criteria in language generation. Proceedings of the sixth conference on European chapter of the Association for Computational Linguistics (pp. 454-459).

Topler, J. (2018). Turning travelogue readers into tourists: Representations of tourism destinations through linguistic features. Cuadernos de Turismo, 42, 447-464.

Wanner, L., \& Bateman, J. (1990). A Collocational based approach to salience sensitive lexical selection. In Proceedings of the Fifth International Natural Language Generation Workshop (pp. 31-38).

\section{Copyrights}

Copyright for this article is retained by the author(s), with first publication rights granted to the journal.

This is an open-access article distributed under the terms and conditions of the Creative Commons Attribution license (http://creativecommons.org/licenses/by/4.0/) 